ARTICLE

https://doi.org/10.1057/s41599-019-0281-2

\title{
Institutionalizing applied humanities: enabling a stronger role for the humanities in interdisciplinary research for public policy
}

Frans W.A. Brom¹,2

\begin{abstract}
What can society expect from the humanities? This question is even more pressing in the discussion on the contribution of the humanities in interdisciplinary research that supports public policy in dealing with societal issues. In the science-based policy community of-mostly natural-scientists, it is clear that there are limitations in natural science approaches to public policy. This community looks at the 'other' disciplines in academia, including the humanities, to overcome these limitations. An analysis of these limitations as actual limits, boundaries, and necessary bounds clarifies what science advisers need from the humanities: to contextualize decontextualized science advice. Unfortunately, there is little structural dialogue between the humanities and the science advice community. One reason for this is the idea held by the humanities that its public task is to unmask power structures rather than to support them. Another reason is the lack of institutional power to engage in practical discussions on policy problems. If the humanities really want to engage in a productive conversation on its societal relevance, they should develop the idea of social impact beyond that of knowledge utilization of specific and individual projects. For many fields of science application, there are institutions in which subject-specific research is combined with knowledge-intensive policy service. The humanities need institutions for applied humanities in order to develop perspectives that help society to cope with important societal challenges.
\end{abstract}

\footnotetext{
${ }^{1}$ Ethics Institute, Faculty of Humanities, Utrecht University, Utrecht, The Netherlands. ${ }^{2}$ Netherlands Scientific Council for Government Policy (WRR), The Hague, The Netherlands. Correspondence and requests for materials should be addressed to F.W.A.B. (email: f.brom@uu.nl)
} 


\section{Introduction}

o the humanities have a contribution for society in coping with societal issues? This general question is even more pertinent in the discussion on the role of the humanities in interdisciplinary research that supports society's collective action in public policy in dealing with societal issues. The question is in line with the discussion in the group of Chief Scientific Advisors of the European Union's Science Advisory Mechanism on 'Making Sense of Science under Conditions of Complexity and Uncertainty' (SAM, 2019). The question is: 'Is there a place for the humanities as academic discipline in making sense of science?' And if the answer to this question is affirmative, can the humanities support policy-making in their current form, or are there institutional implications for taking up this role?

Research in the humanities provides systematic knowledge of how history, social structures, and culture drive individuals, communities and cultures by reflecting on sources and traditions, cultural practices and ways of communication. The interpretive disciplinary traditions of the humanities focus on what it is 'to be human' and are directed at individual and collective self-understanding. This is even more important in a technological age of human enhancement, artificial intelligence, and virtual reality where 'being human' is at risk and in need of specific academic attention. Without self-understanding, societies run the risk of stumbling blindfolded in a globalizing and technologizing world. In the words of the Princeton Task Force on the Future of the Humanities (2015):

"At a time when technology offers dazzling new possibilities and cultures collide in ways both exciting and dangerous, the humanities provide crucial insight into what matters in life, into the character of civilization, and into the capacity - and the limits - of people's ability to understand societies different from their own."

How can these crucial insights of the humanities be made valuable for society? One way ${ }^{1}$ of creating societal value is involving humanities scholars in interdisciplinary research that supports societies in developing collective action in public policy aimed at dealing with societal issues.

In practice, however, we see that there is a limited interaction between interdisciplinary research in policy advice and the humanities. In practice science based policy advice is dominated by the natural and life-sciences, sometimes supplemented with social sciences. But, as I will show in the next section, there is a developing science advice community that realizes the limitations to a natural science based policy advice. This community is interested in an open conversation to broaden the academic base of science advice. In order to develop the role the humanities can play in this field I analyze this idea of limitations to science advice. This analysis of these limitations clarifies what science advisers need from the humanities: context for science advice. The humanities are the academic field per excellence to provide context. In their current situation, however, the humanities are unable to deliver context usable in science advice. The humanities lack institutional power to engage in practical discussions on policy problems. That is why the humanities need-like many other fields-specific institutions in which subject-specific research is combined with knowledge-intensive policy service. I conclude that the society needs institutionalized applied humanities to support it in coping more effectively with its issues.

Development of the science-advice community. In many countries, the interaction between science and public policy is developing from a loose connection between individual scientists and policymakers into organized and transparent structures.
These structures aim to provide policymakers (politicians and civil servants) with relevant and trustworthy science-based policy advice. In my position as secretary/director of the Netherlands Scientific Council for Government Policy (WRR), I see a growing institutionalization and internationalization of science-based strategic policy advice and I see the development of an international community of science advisers with a strong orientation towards natural, biological, environmental, medical and technical sciences (or the 'natural sciences', in short). These structures aim to provide policymakers with relevant and trustworthy sciencebased policy advice.

Building structures for science advice to the government is not new: there has been a Presidential Science Advisory organization in the USA since the 1950s (Bronk, 1974) and a Government Chief Scientific Adviser in the UK since 1964. In an overview of worldwide science and technology advice from 1991 William T. Golden (1991) demonstrates that there were already different models for science advice in different countries back then. In some countries, the focus is on individual scientists providing advice, while in other countries the structures are more geared towards collective and cooperative councils, academies and institutes. In general, one could say that science-based policy advice is organized along the lines of specifically designated individuals, the Chief Scientific Adviser, in the Anglo-Saxon world whereas the expert committee model is more present on the European continent (Gluckman and Wilsdon, 2016).

Given the broad field in which science-based analysis is relevant for policy, the models in most countries, however, are a mixture of different institutional settings. In the Netherlands, for instance, there are more than ten strategic advisory councils that provide independent science-based policy advice to the government and more than 25 public knowledge institutes aiming to do science for policy. According to Koens et al. (2016, p. 1) public knowledge institutes are institutes whose "main raison d'être is therefore not to contribute to the growth of knowledge by means of research-as can be said of the universities-but rather to provide these knowledge-intensive services." And even in the United Kingdom science-based policy advice goes beyond individual Chief Science Advisors (CSA's). As Cooper (2016, p. 9) shows "the scope of science advice-as represented by CSAshas been redrawn to include GSR (Government Social Research). At a superficial level, this includes recognizing that science advice includes social science advice, and that science advice may be undertaken not just by the 'charismatic megafauna' but also other parts of the ecosystem. Importantly, we find that when we look at how one element of that ecosystem-GSR-executes science advice, we find a distinction in the definition of the 'science' aspect becomes pertinent, reflecting the methodological expertize exploited by GSR in provisioning 'science process advice'."

The idea of bringing together the different scientists working as government-allied and policy-oriented science advisers is not new either. In the overview mentioned above, the question of international co-operation was raised by Golden as early as in 1991 (Golden, 1991): "Would an informal, unofficial organization of science and technology advisers to the top levels of governments of the major countries-or of all countries-be useful and viable?" It was argued that such "an organization could be an forum for discussion, for cross-pollination, and for exchange of ideas." The idea of establishing an international community of science advisers has materialized in recent years. An important impetus was given in 2012, when Robert Doubleday and James Wilsdon, two British academics working on the interface between science and policy-making, wrote a commentary in Nature claiming that "Chief scientific advisers need better support and networks to ensure that science advice to 
governments is robust." (Doubleday and Wilsdon, 2012) Their article struck a timely chord with many working at the sciencepolicy interface.

Also in 2012, the European Union appointed Anne Gloverthe first Chief Scientific Adviser to Scotland-as its Chief Scientific Adviser (Kupferschmidt, 2013). She started to compose a forum of science advisers from different European member states, which led to the establishment of the European Science Advisors Forum (www.esaforum.eu). At the same time, the Chief Science Advisor of New Zealand, Sir Peter Gluckman, took the initiative to create a global network of science advisers: the International Network for Government Science Advice (www. ingsa.org), following a declaration of the World Science Forum in 2015 on The Enabling Power of Science (WSF, 2015). ${ }^{2}$ The creation of a science advice community was further supported by academic journals $^{3}$, grants, meetings and authoritative texts (INGSA, 2018, OECD, 2015).

Science advisers share the experience of societal skepticism. The focus on international cooperation in science-based policy advice is rooted in a shared experience: all science advisers have experienced societal skepticism with regard to hard-core scientific findings and have seen that this skepticism has real policy impact. This experience is exemplified by the climate change controversy. ${ }^{4}$ The climate change controversy colors the perspectives of large parts of the scientific community, but more particularly those involved in science-policy interactions. The idea that human behavior is inducing drastic change in our climate (anthropogenic global warming) has been scrutinized and discussed within the scientific community over a long period of time, and there is a strong consensus in this community that their scientific findings should have an impact on human behavior to prevent global warming from getting out of control with immense consequences for human life on earth. As drastic changes in human behavior are needed, it is important to establish clear structures that provide trustworthy evidence for governments, companies and individuals to act on: making clear what we know, what is certain, probable or uncertain, what is uncontroversial and what not and what can we do about it. For this reason, organizations such as the Intergovernmental Panel on Climate Change (IPCC) have been set up to provide a science basis for policies.

There is, however, a problem with this science basis for policy: scientific uncertainty. As science is inherently uncertain, discussion is always possible on every 'trustworthy and uncontroversial' evidence base. It is this uncertainty that is exploited by those who are resisting the policy impacts of global warming and who aim to create doubt and mistrust. In doing so, some scientists are used as 'hired guns' for vested interests. These scientists, think tanks and their financers function as-what Oreskes and Conway (2010) have called-'Merchants of Doubt'.

Answering doubt. Strengthening consensus is the formal response to the doubts raised by the cultivation of uncertainty. Academic leadership in the scientific community and the science advice community search to strengthen consensus and to intensify communication. Allow me to give just one example to make my point. The World Science Forum (WSF, 2015) issued a declaration 'The Enabling Power of Science' showing the impact of this experience. In this-strong worded, slightly pompous, UNstyle-declaration, the second section entitled 'Agreement on Climate Change' starts as follows:

"We endorse the reports and statements published recently by major scientific organizations including IPCC, ICSU, UNESCO, EASAC, and the outcome statement of the international science conference 'Our Common Future under Climate Change' co-organized by UNESCO, ICSU, Future Earth and major research institutions in France in July 2015. It is unequivocal that climate change is strongly influenced by the way we manage our environment, our natural resources, and how we produce and use energy and food. Climate change and its consequences will eventually affect us all"

Followed by:

"Based on the available scientific knowledge it is only by concerted global actions and smart science-informed policies that we can provide solutions to limit warming of the climate system to $2{ }^{\circ} \mathrm{C}$ above pre-industrial levels, and thus reduce the risks and mitigate the consequences of climate change."

Leading, in the fourth section entitled 'Scientific advice for policies', to:

"We are deeply convinced that sound, independent scientific advice largely improves the quality of policymaking. We welcome recent global trends for the more pronounced use of science in policy-making and the efforts to bridge the difficulties inherent in the roles of scientists and policy makers."

The declaration takes a direct route from restating the scientific consensus on global warming to the need for sound, independent scientific advice aiming to improve the quality of policymaking.

Broadening the academic base of science advice. The International Network for Government Science Advice (INGSA) developed an answer to this notion of 'Scientific advice for policies' as promulgated in the WSF declaration in its INGSA Manifesto for 2030-Scientific Advice for the Global Goals. This manifest was drafted between 2016 and 2018 in discussion with practitioners, scholars from a wide range of disciplines and ethicists from around the world. ${ }^{5}$ With this Manifesto, INGSA "aims to provide a framework for discussion and action on the principles and guidelines that underpin effective science advice." (p. 2). The Manifesto explicitly states that science advice needs a basis beyond the natural and life sciences and needs to include the social sciences, as well as the humanities. This position is taken in two steps. First it describes (p. 6) scientific advice inclusively, that is, explicitly including the social sciences and the humanities:

"What, then, is scientific advice? We might say it is the variety of processes and arrangements by which scientific expertize and policy making at different levels of government are brought into productive collaboration to address a variety of types of problems. We might add that the 'scientific' in this context includes evidence and expertize from the social sciences and humanities, as well as natural and physical sciences and engineering."

Then it elaborates this position by looking at (p. 13) the Sustainable Development Goals (SDGs) of the United Nations as a core challenge, stating that science advice directed at the SDGs needs to be more than just 'technical advice':

"In each of the SDGs, natural science, social science, data science, economic and political science and particularly implementation science will be needed. The humanities are also crucial. The SDGs speak to a critical juncture in human history when we are changing our environments, cultures and behaviors at a pace that makes the implications difficult to fully comprehend. The insights of historians, 
philosophers and others are needed to make sense of these changes."

Developing public policy, therefore, requires more than factual evidence. The position of INGSA is line with the experience in the climate change discussion, in which it has been emphasized that facts about climate change alone are not a sufficient basis for developing climate policies. Climate change demands fundamental changes in individual and collective behavior and new social and political institutions. As Hulme (2011, p. 179) argued in Nature Climate Change: "The positivist disciplines are ill-suited to engaging with and articulating the deeper human search for values, purpose and meaning-and yet this search is exactly where humanity's new entanglement with global climate is taking us. To shed new light on the multiple meanings of climate change in diverse cultures, and to create new entry points for policy innovation, the interpretative social sciences, arts and humanities need new spaces for meeting as equals with the positivist sciences."

To conclude, there is an emerging science advice community. This community has a strong basis in the natural and life sciences. Against the background of social skepticism towards hard core scientific findings and the policy impact of this skepticism-as exemplified in the global warming discussionthis community is now organizing itself. To leading figures in this community, it is clear that science advice needs a broader academic basis, and they explicitly mention that the perspective of the humanities is crucial for the further development of effective and trustworthy science advice. There is interest in the humanities and this interest follows from the recognition of the limits of natural science approaches to science advice. This provides an opportunity for the humanities to show some practical societal value of its scholarship. That is why, for elaborating the role of the humanities, we take a closer look at these limitations.

The limits of science in science advice. The limitations of natural science approaches to public policy provoke the interest of the science advice community in other academic disciplines. On the one hand, these limitations signify the otherness of the 'other' disciplines, including the humanities: they might be capable at the other side of these limitations. On the other hand, these limitations also indicate some form of sameness: as colleagues in academia, we share the challenge of these limitations. So we need to take a closer look at the limitations of natural science approaches to public policy'.

It is fruitful to take a spatial perspective in exploring these limitations. Place and borders (as the limitations of place) serve as our conceptual orientation in the world (Malpas, 2017). Difference in limitations indicate differences in identities of what is 'limited'. Are they 'limits' beyond which we cannot go, or are they 'boundaries' that "presuppose a space existing outside a certain definite place and enclosing it."? (Kant, 1996) Building upon this Kantian distinction between limits (Schranken) and boundaries (Grenzen), Rudolf Makkreel (2015, p. 63) distinguishes between three different ways of limiting: 'actual limits of experience', 'boundaries of possible inquiry' and 'necessary bounds of rational intelligibility'. If we analyze the limitations of natural science-based policy advice as actual limits, boundaries or necessary bounds, this will help to clarify what is expected of the 'other' disciplines in academia to overcome these limitations.

Let's first look at limitations as the actual limits of an existing body of knowledge in the natural sciences. Such limits constrain science advice to serve public policy on a certain issue because more knowledge is needed. It is clear that, from within the domain of a specific discipline, current knowledge is open to further inquiries and further research by definition. It is this perspective on limitations that drives the plea for more research (and hence more funding) in order to provide better science for policy. The science advice perspective on the actual limits of natural science is that we need more research because the answers policy needs have 'not yet' been found. Research that will shift these limits will serve to overcome the limitations.

More research, however, is not necessarily the best way to cope with the actual limits. One must also analyze whether-from the perspective of the policy problem and from the perspective of the societal issue-the research question is the adequate question. Understanding the context of a social issue-the socio-historical world-is a necessary step to take in order to determine what scientific expertize might actually be needed. While more research to move the limits might help to overcome the limitations, it might be just as important to change the perspective and open up new experiences. And as the limits of actual knowledge are inherent in knowledge, learning to cope with limits of knowledge is essential for public policy. Communicating, assessing and deciding under uncertainty is only possible if we look beyond the uncertainty of a specific perspective to what is needed to cope with the issues and problems at stake.

In the second perspective, the limitations in the domain of the natural sciences are conceived as the disciplinary boundaries of what can be known using the methods of the natural sciences. If you look from within the domain of a specific discipline, it is difficult to recognize limitations as boundaries of possible inquiry because it is difficult to recognize the boundaries of a certain method with that method itself. The experience of the boundaries of different methods in the natural sciences drives the search for new methods and approaches. The science advice perspective on the boundaries of the natural sciences is: we need different research because the issues that need to be addressed by policy require different scientific perspectives; so if we look for different academic methodologies, this might help us to look beyond our disciplinary boundaries in order to develop better science advice.

It is only possible to look at the humanities as academic disciplines beyond the boundaries of the natural sciences, however, if the boundaries of the humanities themselves are respected. The humanities are not 'natural sciences' with different methods. Beyond the boundaries, there is another domain where different rules apply. This has been an issue in the global warming discussion. Hulme defends (2011, p. 178) that understanding the limitations of the natural sciences as boundaries implies that the "opening-up of climate change to scrutiny from interpretative disciplinary traditions should not be achieved on the terms offered by natural scientists alone. (...) It needs to be acknowledged that the role of arts and humanities is not simply to translate scientific knowledge into public meaning, as though science is the only source of primary knowledge. Neither will the humanities 'solve' the problem of climate change."

In the third perspective, finally, the limitations in the domain of the natural sciences are conceived as the necessary bounds of expert knowledge. These bounds are indicated in the discussion on the distinction between science advice on the one hand and policy-making on the other. This distinction has been described as follows by Sir Peter Gluckman (2014, p. 163): "Science advice is about presenting a rigorous analysis of what we do and do not know. Alone, it does not make policy. There are many other appropriate inputs to policy, including fiscal considerations and public opinion."

Food safety as example. The role of science in setting international food safety standards helps to show the implications of recognizing these bounds. The discussions on food safety 
standards are highly relevant for international food trade, and these standards play a crucial role in trade conflicts between the EU and the USA. When we recognize the bounds of expert knowledge (and not just its limits and boundaries) in these discussions, we see a clash between 'food cultures' with battle lines drawn around GM food, animal welfare, geographical indications and, more recently, chlorine chicken. These battle-lines show the difficulties of translating a socio-cultural issue (what is edible) via a policy problem (what are proper food standards) into a scientific-technical question (scientific risk assessment as basis for international trade).

In the structures for food safety policy, the notion of 'other legitimate factors' has been introduced in order to cope with the 'translational difficulties'. This notion plays a crucial mediating role because it allows socio-cultural elements (recognizing that food is more than just nutrients) being brought into policy decisions based upon scientific risk assessment. The problem, however, is that these factors are not well defined. According to Caswell (2000, p. 119): "There is no definitive list of other factors but they may include: economic interests, food security, animal welfare, environmental impacts, consumer acceptance, and other ethical concerns." This is the case not because of lack of conceptual clarity but because of different geo-political perspectives. Between the USA and the EU, there is "strong disagreement on whether these other factors should be considered and whether they should enter as part of the assessment or management stages of risk analysis" (Caswell, 2000, p. 119). While Europe does not accept 'chlorine chickens' from the USA, food safety is not the core driver of this discussion; the core driver of the discussion is the way we treat food and the USA's 'chemical attitude' towards food safety. (Dawson, 2017) The European hesitance to accept chlorine chicken can be brought into food policies and trade regulations based upon the lack of consumer acceptance. This discussion between the EU and the USA on 'other legitimate factors' shows that international food safety standards are not just a matter of 'technical questions' that can be regulated by a technical/scientific community, but that they are an indication of a wider societal issue and a policy problem in which broader considerations should be taken into account (Brom, 2004).

This analysis of the limitations of natural-science-based policy advice as necessary bounds shows the translational difficulties between societal issues, policy problems, and scientific advice: societal issues are translated into policy problems, which are translated into scientific questions and scientific answers are translated into policy recommendations that aim to help society to cope with the issues. Looking for different academic perspectives might help to reflect on the translational issues and socio-cultural dimensions of these translations. As the food example makes clear, a scientific risk assessment perspective on food that leaves cultural, symbolic, religious and identity aspects of food aside is only of limited help in developing a food policy. ${ }^{6}$

Wicked problems. The necessary bounds of expert knowledge are not only relevant for translating policy problems into scientific questions, but also for translating societal issues into policy problems. Societal issues are often complex, and policies to handle these issues often depend on several actors that have different preferences. These issues cannot be translated into clear problems for which planned, rational and systematic public policy can be developed. This is why these issues give rise to what Rittel and Webber (1973, p. 155) famously call 'wicked problems': "The search for scientific bases for confronting problems of social policy is bound to fail, because of the nature of these problems. They are 'wicked' problems, whereas science has developed to deal with 'tame' problems (...) Wicked problems cannot be characterized, analyzed and planned for by adopting a rational systems perspective, because they cannot be considered as if they were 'tame' or 'benign'; that is definable, separable, and solvable."

As Crowley and Head (2017) showed the idea of looking at policy problems as wicked problems has been very influential in the analysis of the limited role of natural science in environmental policy. In a science advice context wicked problems, with their complexity, dependencies on multi-actor interaction and differences in preferences of involved agents, make clear that planned, rational, and systematic public policy is bounded too. This contextualizes the bounds of science advice. Science advice in the context of policy complexity needs to take principal unpredictability of societal processes into account. Looking for different academic perspectives beyond the natural sciences might help develop a reflexive practice in which this is done.

Contextualizing decontextualized science advice. Based upon our analysis of the expectations of the science-advice community, we can develop a systematic reconstruction of what science advisers need from the 'other academic disciplines'. The actual limits make clear that current knowledge is by definition open to further inquiry and further research and that there are inherent uncertainties in science advice. Coping with the inherent uncertainties of science demands a change in perspective on evidence. Uncertainty is not only a lack of knowledge but also an inherent property of knowledge. The humanities can help to cope with this change in perspective by linking uncertainty to the socio-historical context of the relevant societal issues and policy problems. Reflexive awareness of the issues at stake is crucial for the way we cope with uncertainty.

The disciplinary boundaries make clear that a multidisciplinary approach broadens the knowledge base for public policy. The hope is that the 'other' academic disciplines can broaden the knowledge base by developing comparable knowledge that can be integrated into science advice. It is clear, however, that insights from the interpretive sciences are not comparable in any simple way. Working on different sides of disciplinary boundaries raises the question of how fundamentally different disciplines can be integrated. There are extensive discussions on multi-disciplinary, inter-disciplinary, and transdisciplinary research (e.g., Frodeman et al., 2017) One of the ideas of science-based policy advice is that such integration needs to be problem-based. Problem-based integration, however, demands a deeper understanding of the societal issues and policy problems that are the basis for integrating different disciplinary perspectives. Such a deeper understanding should include awareness of and sensitivity for the socio-historical context in which these issues and problems arise. Humanistic scholarship that reflects upon the socio-historical contexts of the issues and problems can help to develop a reflexive integrating perspective.

The necessary bounds make clear that there are translational difficulties that limit science advice to one policy source among others. From a traditional science advice perspective the 'other' academic disciplines can improve the efficacy of science advice by bringing translation and its socio-cultural dimensions as an explicit element into the development of science advice. More specifically, the humanities might foster understanding of the world 'outbound', that is, again understanding the socio-historical contexts of issues and problems as an aid in coping with the bounds of rational policy-making. Humanities scholarship can foster reflexivity on the limits of rationality in the development of public policy as societies collective action.

The core contribution to science advice of the humanities is recontextualizing decontextualized science advice. In 
interdisciplinary academic research based science advice the humanities can assist science advice to engage with:

- the socio-historical context of societal issues it advises on;

- the diffusion of meaning in transforming these issues into policy problems;

- the translational shifts in formulating scientific questions based upon policy problems;

- the difficulties of translating scientific findings into policy advice; and

- the rhetorical function of such science advice in the deliberations on the development of public policy.

These are all issues that fit in with the expertize developed within the humanities, that is the expertize to assist in understanding the dynamics of interaction between societal issues, policy problems, and scientific evidence in socio-political debates. In this process the humanities might make clear that societal issues and policy problems differ from scientific questions and that in real life not every problem can be solved with the right knowledge.

Living up to expectations?. My analysis of the expectations of the science advice community shows that there is room for a role of the humanities in science advice. This role fits reasonably well with the self-understanding of the humanities. The idea that the humanities really can function in a policy advice structure is not an isolated idea of the science advice community. Academic leaders are signaling that the humanities can help in facing policy challenges. And given the current governance structure in the academic world, this is mostly done under the heading of Social Science and Humanities. One example of such a signal is the advisory paper entitled Social Sciences and Humanities: Essential Fields for European Research and in Horizon 2020, published by the League of European Research Universities (LERU) ${ }^{8}$ in 2012. This paper aims to influence European research funding under the European Horizon 2020 research framework in favor of the social sciences and the humanities. The Executive summary (p. 30) starts as follows:

"Social Science and Humanities (SSH) research is of vital importance to the future of Europe. SSH researchers study the human aspects of the world and they generate important new knowledge which has a deep and intrinsic value. The disciplinary SSH agenda is increasingly complemented by an interdisciplinary agenda addressing societal challenges in Europe. These challenges include international conflicts, human rights (...) psychological disorders, addiction, and man-machine interactions. This understanding is as important as contributions from natural-scientific and technological disciplines to the creation, implementation and evaluation of effective public policies and innovative structures underpinning corporate performance."

This contribution is important because the complexity of the societal challenges requires the entire research base to tackle these complexities (p. 13):

"A broad knowledge economy enables flexibility, creativity and variety of multidisciplinary approaches to tackle these big issues, and Social Science and Humanities research is an essential perspective. (...) Analysis of the past and understanding societies, beliefs and values can be a critical factor in understanding how we can respond effectively to these continuing challenges. SSH research enables us to have a greater understanding of change and adaptation as a process and imagining future scenarios."

And although the LERU report describes the contribution of social sciences and humanities, it is clear that with "analysis of the past and understanding societies, beliefs and values" it explicitly links with scholarship in the humanities. Here, again, we find the idea that collective and individual self-understanding is important for coping with societal issues and policy problems. Scholarship in the humanities provides systematic knowledge that enables policymakers to be more effective in facing societal challenges.

Humanities' individualism. Despite the positive attitude in academic leadership (at least in discussions regarding research funding), there is little interaction between the science advice community and scholars in the humanities. It is my hypothesis that academic and intellectual individualism in the humanities is one of the causes of this lack of interaction. This individualism is substantiated by two different issues that I encounter in discussions with colleagues in the humanities on the engagement of the humanities in science advice: an ideological and a practical issue.

Ideologically, scholars claim that the public task of the humanities is to unmask power structures, not to support them. This self-understanding of the humanities prevents productive collaboration with policy-making from taking place: to engage in science advice is to engage in a power-oriented practice, in which so-called scientific arguments are, in fact, the use of power in disguise. This is a very narrow understanding of expert-based politics and policy-making: politics is a battle; policy-making is dirty; and expertize is interest in disguise. An example of this perspective is clear in the discussions on counterpublicity. Asen (2015, p. 139) defends: "Counterpublicity has enabled rhetorical scholars to produce critical analyses of the dynamics of multiple publics, inclusion-exclusion, and equality-inequality. Reacting against the legitimating discourses of the bourgeois public sphere, which advanced a universalist claim to represent the interests of society as a whole, counterpublic analyses emphasize the multiple character of the contemporary public sphere." It is good to analyze science advice critically as a 'legitimating discourse', but this can only develop into an interdisciplinary dialogue if a more constructive follow up is developed.

This ideological perspective, however, does not necessarily imply that humanities scholars withdraw themselves from the public sphere. On the contrary: they engage in politics as citizens, as public intellectuals and as political activists. Asen (2015, p. 139) formulates as possible tasks for public sphere scholarships: "Scholars may explore challenges to unjust economic arrangements, such as the recent protests of the Occupy movements. Inquiries into dominant discourses and challenges to them both require a consideration of the relationship between material and discursive forces. For example, decisions by politicians to 'bail out' large corporations while leaving ordinary folks to suffer in times of economic crisis demonstrates the power of discourse to reallocate material resources." Again, without constructive follow up, this seems a limited starting point for a productive collaboration with policy-making for coping with societal issues. The consequence of engagement in public sphere scholarship is individual political engagement. For the societal position of the humanities as such, individual political engagement mightperceived as activism-even have negative consequences, creating an image of left-wing scholars who are unable to engage professionally with societal problems and who 'sell' their political opinions cloaked in academic garb.

The practical reason is that there is virtually no organized intermediate structure where expertize in the humanities can have any systematic interaction with other sciences in developing science-based policy advice, which is considered to be the task of individual academics without the benefit of the community of scholars. We also find this perspective in the 'individualized' structures in the governance of the humanities. Both knowledge 
utilization paragraphs in research funding applications and societal relevance in quality monitoring efforts look at the productive interactions of individual research proposals and research groups. As Boswell and Smith (2017) make clear this individual model of analyzing policy 'impact' has a limited perspective on research-policy relations. And in combination with a focus on economic impact (called 'valorization' in Dutch, a misappropriation) in research policy in general and on sociocultural impact in the humanities, this limited perspective on research-policy relations makes it difficult for individual researchers to link their research into the development of public policy. In the humanities, finally, unlike in other academic disciplines, there are very few intermediate institutions where experienced scholars develop systematic interactions with policy (Koens et al., 2016) and there are very few institutions in which subject-specific humanities research is combined with knowledgeintensive interdisciplinary cooperation. ${ }^{9}$

If the humanities want to show public value in a systematic contribution to the development of public policy, then humanities self-understanding needs to develop beyond the ideological perspective sketched above. The humanities need to develop a narrative in which the humanities present themselves not only as a critical factor in our individual and collective self-understanding but also as a helpful factor in societies quest to cope effectively with its challenges. Such a narrative on social relevance needs room for systematic engagement with public policies that aim to support collective action in coping with societal challenges.

In academic policy advice disciplines need to grow beyond academic individualism. This is a challenge for the humanities. This implies firstly, that knowledge utilization should no longer be limited to specific and individual research projects, as individual projects create a hotchpotch of small initiatives in which the humanities are seldom able to go beyond scratching the surface. The role the humanities can play in interdisciplinary research that supports society's collective action in public policy in dealing with societal issues is not something that follows from the utilization paragraph of ordinary research projects. Handling the interaction between academic research and practical issues and problems demands specific professional skills that need to be developed in practice. That is why secondly, the humanities need intermediary structures where developing these skills is an element of academic scholarship. Like in the natural and social sciences there is-next to traditional academic scholarshiproom for academic institutes of applied humanities, where scholars engage in interdisciplinary academic and practical conversations on societal issues and policy problems. ${ }^{10}$

\section{Conclusion}

There is a challenge and an opportunity for the humanities to interact with societal problems and public policies to help society cope with these problems. The science advice community realizes that there are limitations to the natural science approach to public policy and that the 'other' disciplines in academia might help in coping with these limitations. From a systematic analysis of the limitations of science-based policy advice, we learn that these limitations challenge decontextualized science to recontextualize. It fits reasonably well with the self-understanding of the humanities to assist in facing this challenge. Unfortunately, it is difficult for the humanities to engage in a structural dialogue because there is no institutional power to engage in these discussions. From this I conclude that in order to enable a systematic contribution of the humanities in interdisciplinary research that supports society's collective action in public policy in dealing with societal issues, the humanities need institutional structures in which interdisciplinary academic co-operation can be developed.

\section{Data availability}

Data sharing not applicable to this article as no datasets were generated or analyzed during the current study.

Received: 2 April 2019 Accepted: 13 June 2019

Published online: 09 July 2019

\section{Notes}

1 I do not claim that this is the only way to show "The value of the humanities" (cf. Small, 2013)

2 Declaration of the 2015 Budapest World Science Forum on The Enabling Power of Science. http://www.sciforum.hu/declaration/index.html. Accessed 30 June 2018. In this declaration, the WSF describes itself as follows: "World Science Forum (WSF), an outcome of the 1999 World Conference on Science, is a biennial event that since 2003 has been successfully assembling scientists, decision-makers from the world of politics and industry, representatives of civil society and the media to discuss critical global issues and the contribution of science towards meeting the challenges they present."

3 Journals like Science and Public Policy (since 1974); Environmental Science and Policy (since 1998); Evidence and Policy: A Journal of Research, Debate and Practice (since 2005). Palgrave Communications Collection Scientific advice to governments (Since 2016)

4 There are several other cases where the interlinkage between science advice and policy development are influenced by skeptical societal perspectives, such as the antivax movement or GM safety. For an analysis of a few cases, see Blankesteijn et al. (2014).

5 INGSA, Manifesto: In drafting the manifesto, INGSA tried to include a broad scope of authoritative science perspectives and co-organized meetings with the European Union Science Advisory Mechanism (Sept 2016); Global Young Academy workshop in Brussels (Sept 2016); the Science Forum South Africa in Pretoria (Dec 2016); the first Arab Leadership Dialogue on Science Advice to Governments at the Dead Sea Jordan (Dec 2016); the AAAS Annual Meeting in Boston, USA (Feb 2017); MCCBerlin and Stiftung Mercator in Berlin (April 2017); OECD/JRC/Campbell Collaboration Paris (June 2017).

6 Makkreel (2015, p. 75): "The confusion resulting from not properly adjusting to different contexts is a form of what was referred to earlier as Kant's amphiboly of concepts of reflection. For our hermeneutical approach, this amphiboly points to the need to treat distinctively each of our six ways of contextualizing a subject matter. (...). Most of all we must cultivate a structural awareness of how fields, domains, territories, habitats, and systems-based and medium-focussed contexts may or may not intersect."

7 I am making a conceptual claim about what the science advice community needs, not an empirical claim about what it recognizes as needs.

8 The LERU was founded in 2002 as an association of research-intensive universities sharing the values of high-quality teaching in an environment of internationally competitive research. Its members are: Universiteit van Amsterdam, Universitat de Barcelona, University of Cambridge, University of Edinburgh, Albert-LudwigsUniversität Freiburg, Université de Genève, Universität Heidelberg, Helsingin yliopisto (University of Helsinki), Universiteit Leiden, KU Leuven, Imperial College London, University College London, Lunds universitet, Università degli Studi di Milano, Ludwig-Maximilians-Universität München, University of Oxford, Université Pierre et Marie Curie, Paris, Université Paris-Sud 11, Université de Strasbourg, Universiteit Utrecht, Universität Zürich. www.leru.org. Accessed 30 Nov 2018.

9 Where these institutions exist-e.g., ethics institutes, philosophy groups at technical universities or bioethics groups-they are able to develop a basis for this conversation.

10 This is in line with Koenig (2019, p. 20) who writes on the integration of SSH research in interdisciplinary EU-funded research that "it is also important to be ready, and to muster capacity, to take over the consortium coordination, in order to stronger influence the tone for a project. On a related matter, it is crucial to ask for local support infrastructure. SSH sometimes have the disadvantage of not being supported the same way as their STEM colleagues are."

\section{References}

Asen R (2015) Critical engagement through public sphere scholarship. Q J Speech 101(1):132-144 
Blankesteijn M, Munnichs G, Van Drooge L (2014) Contested science: public controversies about science and policy Rathenau Instituut, Den Haag. https:// www.rathenau.nl/en/kennisgedrevendemocratie/contested-science

Boswell C, Smith K (2017) Rethinking policy 'impact': four models of researchpolicy relations. Pal Commun 3(44):1-10. https://doi.org/10.1057/s41599017-0042-z

Brom FWA (2004) WTO, public reason and food; public reasoning in the 'trade conflict' on GM-food. Ethic Theory Moral Pract 7(no. 4):417-431. https:// doi.org/10.1007/s10677-004-2221-4

Bronk DW (1974) Science advice in the white house: the genesis of the president's science advisers and the national science foundation. Science 186(no. 4159):116-121. 1974

Caswell JA(2000) An evaluation of risk analysis as applied to agricultural. Biotechnology (With a Case Study of GMO Labeling) Agribusiness 16 (1):115-123

Cooper ACG(2016) Exploring the scope of science advice: social sciences in the UK government. Pal Commun 2(160044):1-9

Crowley K, Head BW (2017) The enduring challenge of 'wicked problems': revisiting Rittel and Webber. Policy Sci 50(no. 4):539-547. https://doi.org/ 10.1007/s11077-017-9302-4. 2017

Dawson S (2017, August 2) Chlorine-washed chicken Q\&A: food safety expert explains why US poultry is banned in the EU. The Conversation https://www. theconversation.com. Accessed 30 Nov 2018.

Doubleday R, Wilsdon J (2012) Beyond the great and good. Nature 485(17 May 2012):301-302. https://doi.org/10.1038/485301a

Frodeman R, Thompson Klein J, Pacheco RCS (eds) (2017) Oxford handbook on interdisciplinarity. 2nd edn. Oxford University Press, Oxford/New York

Gluckman P (2014) The art of science advice to government. Nature 507:163-164. https://doi.org/10.1038/507163a

Gluckman P, Wilsdon J (2016) From paradox to principles: where next for scientific advice to governments? Palgrave Commun 2(2016):1-3. https://doi. org/10.1057/palcomms.2016.77

Golden WT (ed) (1991) Worldwide science and technology advice to the highest levels of government. Pergamon Press, New York

Hulme D (2011) Meet the humanity. Nat Clim Change 1:177-179

INGSA (2018) The INGSA Manifesto for 2030-Scientific Advice for the Global Goals. International Network for Government Science Advice. www.ingsa. org. Accessed 25 May 2018

Kant I (1996) Prolegommena to any future metaphysics. Routledge, London

Koenig T (2019) SSH-impact pathways and SSH-integration in EU Research Framework Programmes (IHS working paper 5). Institut für Höhere StudienInstitute for Advanced Studies (IHS), Wien

Koens L, Chiong Meza C, Faasse P, De Jonge J (2016) Public knowledge organisations in the Netherlands-facts and figures. Rathenau Instituut, Den Haag. https://www.rathenau.nl/en/sciencefigures/investments/income-andexpenditure-public-knowledge-institutes/public-knowledge

Kupferschmidt K (2013) Profile Anne Glover: Europe's science superwoman struggles to get off the ground. Science 339:1144-1147. https://doi.org/ $10.1126 /$ science.339.6124.1144

Makkreel RA (2015) Orientation and judgement in hermeneutics. University of Chicago Press, Chicago/London

Malpas J (2017) Placing understanding/understanding place. SOPHIA 56:379-391. https://doi.org/10.1007/s11841-016-0546-9
OECD (2015) Scientific advice for policy making: the role and responsibility of expert bodies and individual scientists oecd science, technology and industry policy papers, No. 21. OECD Publishing, Paris

Oreskes N, Conway EM (2010) Merchants of Doubt: How a handful of scientists obscured the truth on issues from tobacco smoke to global warming. Bloomsbury, London

Rittel HWJ, Webber MM (1973) Dilemmas in a general theory of planning. Policy Sci 4(no. 2):155-169

SAM (2019) The Scientific Advice Mechanism to support the Commission with high quality, timely and independent scientific advice for its policy-making activities. Making Sense of Science under Conditions of Complexity and Uncertainty. http://ec.europa.eu/research/sam/index.cfm?pg=science. Accessed 1 Apr 2019

Small H (2013) The value of the humanities. OUP, Oxford

Task Force on the Future of the Humanities (2015) Princeton University. https:// www.princeton.edu/strategicplan/taskforces/humanities/. Accessed 30 June 2018

WSF 2015. Declaration of the 2015 Budapest World Science Forum on The Enabling Power of Science http://www.sciforum.hu/declaration/index.html. Accessed 30 June 2018

\section{Acknowledgements}

A draft of this paper was presented at the workshop 'The humanities of the future. Crosscultural hermeneutics in a globalizing world' at Utrecht University, 19 June 2018. I thank the participants of the workshop and Rudolf Makkreel, Corien Prins, Huub Dijstelbloem, Anne-Greet Keizer, and Lonneke Poort for their helpful comments.

\section{Additional information}

Competing interests: The author declares no competing interests.

Reprints and permission information is available online at http://www.nature.com/ reprints

Publisher's note: Springer Nature remains neutral with regard to jurisdictional claims in published maps and institutional affiliations.

(c) (i) Open Access This article is licensed under a Creative Commons Attribution 4.0 International License, which permits use, sharing, adaptation, distribution and reproduction in any medium or format, as long as you give appropriate credit to the original author(s) and the source, provide a link to the Creative Commons license, and indicate if changes were made. The images or other third party material in this article are included in the article's Creative Commons license, unless indicated otherwise in a credit line to the material. If material is not included in the article's Creative Commons license and your intended use is not permitted by statutory regulation or exceeds the permitted use, you will need to obtain permission directly from the copyright holder. To view a copy of this license, visit http://creativecommons.org/ licenses/by/4.0\%

(c) The Author(s) 2019 